\title{
NOTE
}

\section{BIODIVERSITY OF ZOOBENTHOS AT THE CA RIVER, VIETNAM}

\author{
Chien Nguyen Huy \\ Institute of Fisheries Economics and Planning \\ Quynh NGUYEN XUAN \\ Faculty of Biology, Hanoi College of Science, VNU - Hanoi \\ e-mail: chienncs2003@yahoo.com
}

\begin{abstract}
A research on zoobenthos biodiversity was carried out from September 2004 to September 2006 at the Ca river (the length of Nghe An and Ha Tinh provinces) showed a species composition consisted of 154 species, 115 genera, 72 families, 32 orders and 5 phyla, including Mollusca, Annelida, Arthropoda, Echinodermata and Sipuncula. The results showed that a decreasing trend in the number of zoobenthos species from the fresh water area to the estuary of the Ca River. The largest number of species was shown in route 1 (Cua Hoi) with 89 species (nearly $44.7 \%$ ). The lowest value of species number was seen at route 5 with 31 species $(15.5 \%)$. The Crustacea group was the most predominant group, including 47 species. The $\mathrm{H}^{\prime}$ and $\mathrm{d}$ indexes indicated a decreasing biodiversity level from route 5 (Hung Lam, $\mathrm{H}^{\prime}=0.9$ and $\mathrm{d}=0.75$ ) to route 1 (Cua Hoi, $\mathrm{H}^{\prime}=2.32$ and $\mathrm{d}=1.96$ ). The average number of zoobenthos density was 149 individuals per $\mathrm{m}^{2}$. The average value in dry season was higher than that in rainy season ( 151 individuals per $\mathrm{m}^{2}$ compared to 146 individuals per $\mathrm{m}^{2}$, respectively). In the dry season, the biological indexes changed mainly according to salinity and turbidity factors. Meanwhile, in rainy season, the variation of zoobenthos species related essentially to other factors, DO and salinity.
\end{abstract}

Keywords: Biodiversity, Ca River, Invertebrate, Zoobenthos, Density

\section{INTRODUCTION}

The Ca River is the longest river in the central part of Vietnam, the main length belongs to Nghe An and Ha Tinh provinces. This river possesses abundant natural resources and habitats of many valuable plants and animals, of which some are said to be endangered (listed in the Red Book of Vietnam). The river has also been defined as one of thirteen main fishing places of Vietnam. Moreover, the river is a zone used for shrimp and other aquatic animal exploitation (Ministry of Natural resources and Environment - Action Plan for Biodiversity). Not only taking an important role in ecologically balancing and biodiversity reservation of that river, zoobenthos are critical in economic development of these provinces. Furthermore, characteristics of species composition of zoobenthos could be used as bioindicators for assessing water environmental quality (Tang, 1994; 1997; 2003).
However, the improper usage of the natural resources is causing many seriously negative effects on living habitats. Therefore, it leads to biodiversity decline of that river, which is important for aquatic culture and exploitation. Still now, there have not been many biological researches at the Ca River, except some works of invertebrates conducted by Nguyen Huy Chien et al. (2003a; $2003 \mathrm{~b} ; 2005 \mathrm{a} ; 2005 \mathrm{~b}$ ). Consequently, it is strongly demanded to have more researches on zoobenthos biodiversity at the $\mathrm{Ca}$ River.

\section{MATERIALS AND METHODS}

This research was carried out from September 2004 to September 2006 at the Ca river (the length of Nghe An and Ha Tinh provinces). We conducted 5 collecting routes based on the salinity, including route $1: 18-30 \%$, route $2: 8-17 \%$; route $3: 2-8 \%$; route $4: 0.5-2 \%$; route $5:<0,5 \%$. The map of collecting sites was shown in Figure 1. Samples were collected by Pond net and the stan- 


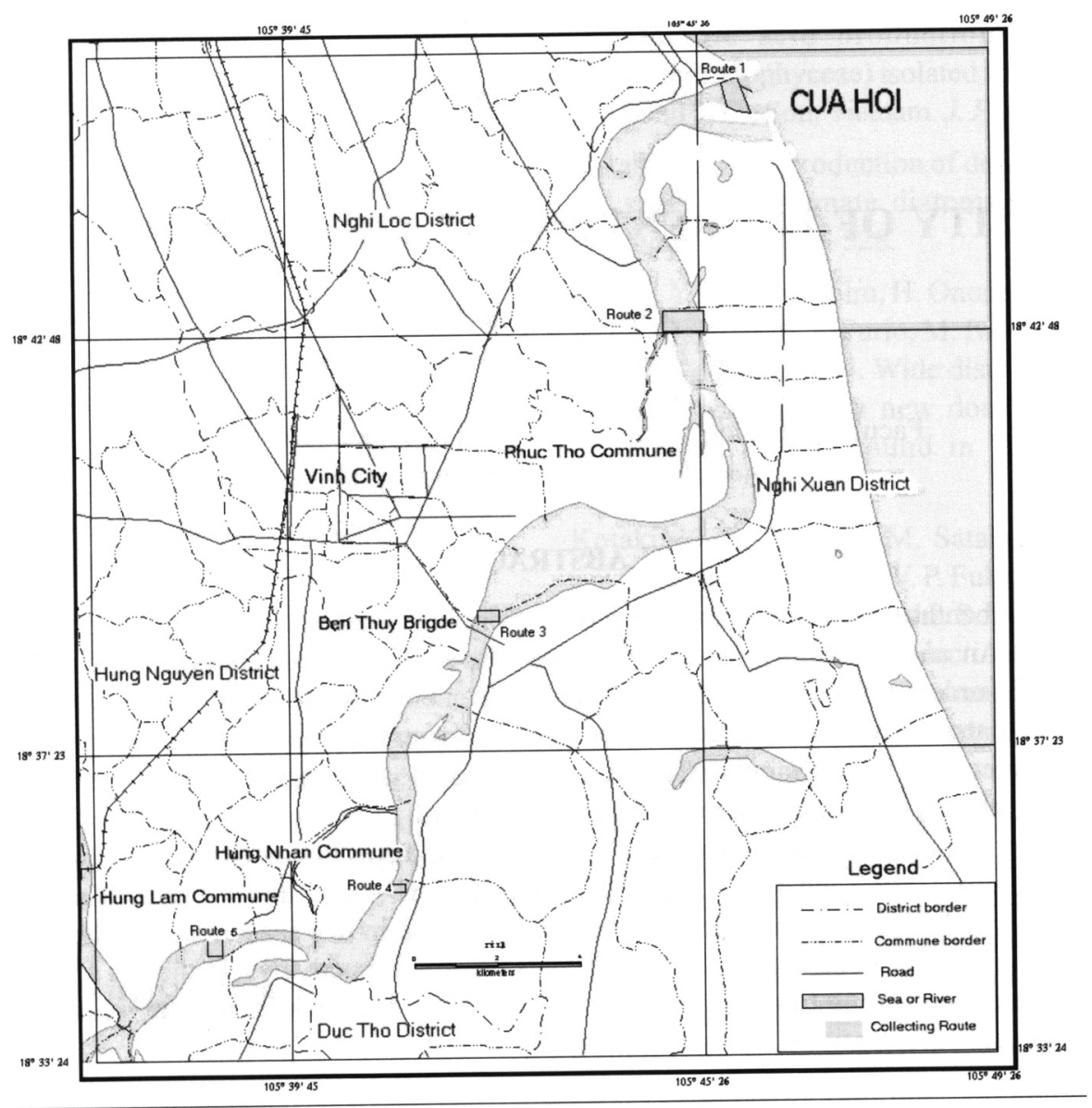

Figure 1. The map showing the collecting sites.

dard quadrate $\left(0.25 \mathrm{~m}^{2}\right.$ in area and $30 \mathrm{~cm}$ in depth) for each route. Moreover, zoobenthos specimens were caught by buying directly from fishers and in local markets. The participatory rural appraisal method also was used to get related information from civilians.

The identification of species was performed according to the key books reported in Vietnam and oversea countries. Then, the data was statistically processed by Microsoft Excel.

\section{RESULTS AND DISCUSSION}

\section{Species composition of zoobenthos fauna}

The analysis result revealed a zoobenthos fauna consisted 154 species belonging to 115 genera, 72 families, 32 orders, 11 classes and 5 phyla (Mollusca, Anneilida, Arthropoda, Echinodermata, Sipuncula); provides for more details. Some main phyla could be discussed as followed (Table 1).
Mollusca phylum has the largest species number with 68 species (48\%) covering 48 genera, 34 families and 17 orders and 4 phyla. Among these species, Gastropoda group had 35 species $(22.7 \%)$. In contrast, Bivalvia group possessed 29 species. These animals were used for many purposes such as export, materials for art objects and so on. Especially, some of Veneroida order were very valuable species, including Glaucomya chinensis, Meretrix meretrix, Tapes literatus. Other economically and conservatively important species named as Anadara nodifera, A. granora, Pinna bicolor, Perna viridis.

Besides, Arthropoda phylum, which has 51 species $(32 \%)$, Crustacea class contributes to a main part of that number with 47 species $(30.5 \%)$. Particularly, 32 species of Decapoda order have been faced on many serious exploiting problems. Many other species played an important role on daily life of inhabitants and aquatic ecology, such as Penaeus monodon, Metapenaeus ensis, Scylla serrata, Portunus pelagicus. 
Table 1. Taxon number of zoobenthos at the Ca River.

\begin{tabular}{|c|c|c|c|c|c|c|c|}
\hline \multirow{2}{*}{ No. } & \multirow{2}{*}{ Phylum } & \multirow{2}{*}{ Class } & \multirow{2}{*}{ Order } & \multirow{2}{*}{ Family } & \multirow{2}{*}{ Genus } & \multicolumn{2}{|c|}{ Species } \\
\hline & & & & & & Number & $\%$ \\
\hline \multirow{4}{*}{1.} & \multirow{4}{*}{ Mollusca } & Gastropoda & 9 & 17 & 24 & 35 & 22.7 \\
\hline & & Bivalvia & 5 & 14 & 21 & 29 & 18.8 \\
\hline & & Cephalopoda & 2 & 2 & 2 & 3 & 1.9 \\
\hline & & Polyplacophora & 1 & 1 & 1 & 1 & 0.6 \\
\hline \multirow{2}{*}{2.} & \multirow{2}{*}{ Annelida } & Polychaeta & 3 & 10 & 23 & 32 & 20.8 \\
\hline & & Olygochaeta & 1 & 1 & 1 & 1 & 0.6 \\
\hline \multirow{3}{*}{3.} & \multirow{3}{*}{ Arthropoda } & Crustacea & 5 & 21 & 37 & 47 & 30.5 \\
\hline & & Insecta & 3 & 3 & 3 & 3 & 1.9 \\
\hline & & Merostomata & 1 & 1 & 1 & 1 & 0.6 \\
\hline 4. & Echinodermata & Asteroidea & 1 & 1 & 1 & 1 & 0.6 \\
\hline 5. & Sipuncula & Sipunculoidea & 1 & 1 & 1 & 1 & 0.6 \\
\hline \multicolumn{3}{|c|}{ Total } & 32 & 72 & 115 & 154 & 100 \\
\hline
\end{tabular}

Moreover, there were 33 identified species (21.4\%) of Annelida phylum and most of these belong to Polychaeta class (32 species, nearly $20.8 \%$ ). These species were exploited as food for inhabitants as well as aquaculture, and many other economic purposes.

Zoobenthos groups according to the collecting routes

The result showed a decreasing trend in values of species number from the fresh water area to the estuary of the Ca River. The largest number of species was reported in route 1 (Cua Hoi) with 89 species, accounted for $44.7 \%$. In contract, the lowest diversity route was route 5 with 31 species $(15.5 \%)$. In this route, Gastropoda is identified for 4 species $(6.1 \%)$, which compared to 22 species (33.8\%), the largest number of Gastropod, in route 2. This phenomenon could be explained by a reason that route 2 is a brackish water zone, including mangrove forests, favorable for the growth of Gastropoda species and many zoobenthos groups inhabiting in mud and sand habitats.
Polychaeta and Crustacea (Decapoda mainly) were two groups which remain stable number of species between the routes. The largest one was found in the route 1 with 18 species of Polychaeta and 32 species of Crustacea. Meanwhile, only seven species of Polychaeta and 15 species of Crustacea were reported at route 5. In short, the number of species of these two groups decreased slightly from route 1 to route 5 corresponding to different ecological characteristics habitats. Table 2 gives more details for the discussions above.

\section{Biodiversity level calculated by applying Shannon Wiener and Margalef methods}

By applying Shannon Wiener and Margalef indexes ( $d$ and $H^{\prime}$ ), it could be found that the level of biodiversity ranged from low level to fairly high level, e.g. H' varied from 0.9 to 2.32 ; $\mathrm{d}$ varied from 0.75 to 1.96 . The results were shown in Table 3. The highest average level of biodiversity was at the Hoi estuary (route 1) with $\mathrm{H}^{\prime}=2.32$ and $d=1.96$. The max values of $H^{\prime}$ and $d$ were 2.9 and 2.6, respectively in this route. Meanwhile,

Table 2. The species number of zoobenthos at the Ca River.

\begin{tabular}{|c|c|c|c|c|c|c|}
\hline \multirow{2}{*}{ Route } & \multicolumn{5}{|c|}{ Zoobenthos groups } & \multirow{2}{*}{ Total } \\
\cline { 2 - 7 } & Gastropoda & Bivalvia & Polychaeta & Crustacea & Other & \\
\hline R1 & 13 & 18 & 18 & 32 & 8 & $\mathbf{8 9}$ \\
\hline R2 & 22 & 14 & 15 & 27 & 4 & $\mathbf{8 2}$ \\
\hline R3 & 14 & 11 & 13 & 22 & 1 & $\mathbf{6 1}$ \\
\hline R4 & 7 & 10 & 8 & 20 & 5 & $\mathbf{5 0}$ \\
\hline R5 & 4 & 5 & 7 & 15 & - & 31 \\
\hline Total & $\mathbf{3 5}$ & $\mathbf{2 9}$ & $\mathbf{3 2}$ & $\mathbf{4 7}$ & $\mathbf{1 1}$ & 154 \\
\hline
\end{tabular}


Table 3. Diversity level of Zoobenthos of the Ca River (calculated by Shannon Wiener and Margalef methods).

\begin{tabular}{|c|c|c|c|c|c|c|c|c|c|c|}
\hline \multirow{2}{*}{ Route } & \multicolumn{2}{|c|}{$\begin{array}{c}\text { Dry season } \\
2004\end{array}$} & \multicolumn{2}{|c|}{$\begin{array}{c}\text { Dry season } \\
2005\end{array}$} & \multicolumn{2}{|c|}{$\begin{array}{c}\text { Rainy season } \\
2004 \\
\end{array}$} & \multicolumn{2}{|c|}{$\begin{array}{c}\text { Rainy season } \\
2005 \\
\end{array}$} & \multicolumn{2}{|c|}{ Average } \\
\hline & $\mathbf{H}^{\prime}$ & d & $\mathbf{H}^{\prime}$ & $d$ & $H^{\prime}$ & D & $\mathbf{H}^{\prime}$ & d & $H^{\prime}$ & d \\
\hline R1 & 2.73 & 2.23 & 1.85 & 1.45 & 1.8 & 1.55 & 2.9 & 2.6 & 2.32 & 1.96 \\
\hline $\mathbf{R} 2$ & 2.65 & 2.6 & 2.08 & 1.4 & 2.13 & 2 & 1.95 & 1.6 & 2.2 & 1.9 \\
\hline R3 & 1.78 & 1.37 & 0.36 & 0.6 & 0.36 & 1.13 & 1.95 & 1.7 & 1.11 & 1.2 \\
\hline R4 & 2.05 & 1.8 & 1.83 & 1.47 & 2.37 & 1.92 & 1.9 & 1.6 & 2.04 & 1.7 \\
\hline R5 & 1.63 & 1.3 & 0.55 & 0.4 & 0.5 & 0.7 & 0.9 & 0.6 & 0.9 & 0.75 \\
\hline Average & \multicolumn{4}{|c|}{$H^{\prime}=1.1 ; d=0.85$} & \multicolumn{4}{|c|}{$H^{\prime}=0.7 ; d=0.65$} & & \\
\hline
\end{tabular}

the lowest average level was found at Hung Lam estuary (route 5), showing $\mathrm{H}^{\prime}=0.9$ and $\mathrm{d}=0.75$. There was the most similarity of biodiversity level in route 2 (Phuc Tho) and route 4 (Hung Nhan), in which $\mathrm{H}^{\prime}$ index varied from 2.04 to 2.2 and $\mathrm{d}$ index ranged from 1.7 to 1.9 .

There were some reasons for these phenomena. Firstly, it can be explained by problems of bad quality of water environment caused by wastewater in route 5 and route 2 , including large amount of wastewater ejecting directly from Vinh City and Lam River Paper Company. Therefore, $\mathrm{pH}$ index was mostly in high level and sometimes exceeded the standard level of Vietnam. The second reason was the serious erosion caused by strong water flow in the La River and $\mathrm{Ca}$ River.

\section{Density of zoobenthos at the Ca River}

The average density of zoobenthos was 149 individuals per $\mathrm{m}^{2}$, and the average value in dry season was higher than that in rainy season, 151 individuals per $\mathrm{m}^{2}$ vs. 146 individuals per $\mathrm{m}^{2}$, respectively. The numbers of zoobenthos groups at brackish and marine waters were mostly higher than those in fresh water areas; the differences were clear in rainy season, table 4.

In dry season, the number of zoobenthos species varied from 30 to 81 species and the average density showed a large range from 69 to 249 individuals per $\mathrm{m}^{2}$. There was an increasing salinity gradient from route $5(0.65 \%)$ to route 1 $(15.5 \%)$ and a rising tendency of turbidity from route $1(4 \mathrm{mg} / \mathrm{l})$, route $2(7.6 \mathrm{mg} / \mathrm{l})$ and route 3 $(21.1 \mathrm{mg} / \mathrm{l})$. Simultaneously, the number of zoobenthos got the minimum value at route 5 ( 30 species), and reached the maximum peak at the route 1 ( 81 species). In contrast, the density had the lowest value at route 1 (69 individuals per $\mathrm{m}^{2}$ ) and then got higher ones at route 2 and route 3 ( 88 and 231 individuals per $\mathrm{m}^{2}$, respectively).

The species number of zoobenthos at different routes according to different periods of time varies from 1 to 19 species. Route 5 always showed the lowest values of zoobenthos groups. And the number of zoobenthos species living in brackish water areas was higher than that in fresh water areas.

The average density of zoobenthos varied from 67 to 326 individuals per $\mathrm{m}^{2}$; and the minimum

Table 4. Average species number and density of zoobenthos in 2004 and 2005.

\begin{tabular}{|c|c|c|c|c|c|}
\hline \multirow{3}{*}{ Route } & \multicolumn{4}{|c|}{ Seasons } & \multirow{3}{*}{$\begin{array}{l}\text { Average Density } \\
\text { (individuals } / \mathrm{m}^{2} \text { ) }\end{array}$} \\
\hline & \multicolumn{2}{|c|}{ Dry season } & \multicolumn{2}{|c|}{ Rainy season } & \\
\hline & $\begin{array}{l}\text { Number of } \\
\text { Species }\end{array}$ & $\begin{array}{c}\text { Density } \\
\text { (Individual/m²) }\end{array}$ & $\begin{array}{l}\text { Number of } \\
\text { Species }\end{array}$ & $\begin{array}{c}\text { Density } \\
\text { (Individual/m²) }\end{array}$ & \\
\hline R1 & 81 & 69 & 62 & 76 & 72.5 \\
\hline $\mathbf{R 2}$ & 73 & 88 & 66 & 192 & 140 \\
\hline R3 & 55 & 221 & 49 & 431 & 326 \\
\hline R4 & 44 & 249 & 34 & 27 & 138 \\
\hline R5 & 30 & 128 & 30 & 7 & 67 \\
\hline Total & & 151 & & 146 & 149 \\
\hline
\end{tabular}


Table 5. Composition of zoobenthos species in rainy and dry seasons at the Ca River.

\begin{tabular}{|c|c|c|c|c|c|c|c|c|}
\hline \multirow[b]{2}{*}{ Route } & \multicolumn{2}{|c|}{ Dry season 2004} & \multicolumn{2}{|c|}{ Rainy seasonMura 2004} & \multicolumn{2}{|c|}{ Dry season 2005} & \multicolumn{2}{|c|}{ Rainy season 2005} \\
\hline & $\begin{array}{c}\text { Number } \\
\text { of } \\
\text { species }\end{array}$ & $\begin{array}{c}\text { Density } \\
\text { (Individuals } / \mathrm{m}^{2} \text { ) }\end{array}$ & $\begin{array}{l}\text { Number } \\
\text { of species }\end{array}$ & $\begin{array}{c}\text { Density } \\
\text { (Individuals } / \mathrm{m}^{2} \text { ) }\end{array}$ & $\begin{array}{c}\text { Number } \\
\text { of } \\
\text { species }\end{array}$ & $\begin{array}{c}\text { Density } \\
\text { (Individuals } / \mathrm{m}^{2} \text { ) }\end{array}$ & $\begin{array}{c}\text { Number } \\
\text { of } \\
\text { species }\end{array}$ & $\begin{array}{c}\text { Density } \\
\text { (Individuals } / \mathrm{m}^{2} \text { ) }\end{array}$ \\
\hline R1 & 18 & 121 & 12 & 91.5 & 9 & 17.5 & 9 & 60 \\
\hline R2 & 17 & 123 & 21 & 189 & 10 & 54.2 & 11 & 195 \\
\hline R3 & 15 & 98 & 15 & 793 & 8 & 344 & 11 & 70 \\
\hline R4 & 14 & 254 & 6 & 24.2 & 19 & 245 & 6 & 30 \\
\hline R5 & 11 & 242 & 1 & 3 & 3 & 14 & 3 & 10 \\
\hline
\end{tabular}

density of zoobenthos was seen at route 5 (about 3 individuals per $\mathrm{m}^{2}$ ). In rainy season 2004 , route 3 had the highest value of density with 793 individuals per $\mathrm{m}^{2}$ (the species Corbicula castanea was predominant with 720 individuals per $\mathrm{m}^{2}$ ). This figure could be explained by large amount of organic wastewater released directly from Vinh City into the river; or related to the reproductive period of many species living in that area (Table 5).

\section{CONCLUSION}

Analytical results of the zoobenthos survey at the Ca river (the length belonging to Nghe An and Ha Tinh provinces, Vietnam) from 2004 to 2006 were summarized as followed:

1) The composition of zoobenthos including 154 species, 115 genera, 72 families, 32 orders and 5 phyla, e.g. Mollusca, Annelida, Arthropoda, Echinodermata and Sipuncula. Molusca phylum possessed the largest species number with 68 species, counted to $44 \%$.

2) The result showed a decreasing trend in the number of zoobenthos species from the fresh water areas to the estuary of the Ca River. The largest number of species was shown in route 1 (Cua Hoi) with 89 species, nearly $44.7 \%$. The lowest was seen at route 5 with 31 species $(15.5 \%)$. The Crustacea group was the most predominant group, 47 species. Moreover, the species numbers of Gastropoda, Polychaeta and Bivalvia groups were 35, 32 and 29 species, respectively.

3) There was also an increasing biodiversity level of zoobenthos from route 5 (Hung Lam, H' = 0.9 and $\mathrm{d}=0.75$ ) to route 1 (Cua Hoi, $\mathrm{H}^{\prime}=$ 2.32 and $d=1.96$ ). Thus, the biodiversity lev- els changed from low diversity level to fairy high level ( $\mathrm{H}$ ' index varied from 0.9 to 2.32 ; and D index varied from 0.75 to 1.96 ).

4) The average value of zoobenthos density was 149 individuals per $\mathrm{m}^{2}$ and the number in dry season was higher than that in rainy season ( 151 individuals per $\mathrm{m}^{2}$ compared to 146 individuals per $\mathrm{m}^{2}$, respectively). In the dry season, the biological indexes levels changed according to salinity and turbidity factors. Meanwhile, in rainy season, the number mainly related to DO and salinity ones.

\section{REFERENCES}

Chien Nguyen Huy, Quynh Nguyen Xuan, 2003 a. Biodiversity of zoobenthos of some shrimp ponds in Hung Hoa and Nghi Xuan Districts - Ha Tinh province. Summary record of national workshop in aquaculture. Agriculture publishing House, 2004.

Chien Nguyen Huy, Quynh Nguyen Xuan, 2003b. Relationship between zooplanktons, zoobenthoss and productivity of shrimp culture in some shrimp ponds in Hung Hoa - Vinh, Nghi Xuan - Ha Tinh. Summary record of national workshop in aquaculture. Agriculture publishing House, 2004

Chien Nguyen Huy, Quynh Nguyen Xuan, 2005a. Preliminary investigation of macroinvertebrate resource at the Ca estuary. Science journal, Vietnam National University, Hanoi.

Chien Nguyen Huy, Quynh Nguyen Xuan, Trong Pham Đinh, 2005b. Some research results on Polychaeta at the Ca river and some surrounding shrimp ponds. National programme for basic research on life science. Science and Technique Publishing House, Hanoi, 2005.

Tang Vu Trung. 1994. Vietnam estuary ecosystems. Science and Technique Publishing House, Hanoi. 
Tang Vu Trung, 1997. Biological estuary resource and ecological impacts caused by human activities. The first national conference on marine biology, pages 79-85.
Thanh Dang Ngoc. 2003. Gulf of Tokin: organisms and ecosystems. Volume IV, Vietnam National University, Hanoi. 